\title{
Corrigendum: Olbert's Kappa Fermi and Bose Distributions
}

\section{R. A. Treumann ${ }^{1,2}$ and Wolfgang Baumjohann ${ }^{3 *}$}

${ }^{1}$ International Space Science Institute (ISSI), Bern, Switzerland, ${ }^{2}$ Geophysics, Department Geoscience and Environment, Ludwig Maximilian University of Munich (LMU), Munich, Germany, ${ }^{3}$ Space Research Institute (IWF), Austrian Academy of Sciences, Graz, Austria

Keywords: Kappa distribution, Fermi- and Bose distributions, solid state and condensed matter, quantum distributions, degenerate matter, entropy

\section{A Corrigendum on}

\section{OPEN ACCESS}

Edited and reviewed by: George Livadiotis, Southwest Research Institute (SwRI), United States

${ }^{*}$ Correspondence: Wolfgang Baumjohann Wolfgang.Baumjohann@oeaw.ac.at

Specialty section: This article was submitted to Space Physics, a section of the journa Frontiers in Physics

Received: 29 May 2021 Accepted: 22 June 2021

Published: 06 July 2021

Citation:

Treumann RA and Baumjohann W (2021) Corrigendum: Olbert's Kappa

Fermi and Bose Distributions. Front. Phys. 9:716892. doi: 10.3389/fphy.2021.716892

\section{Olbert's Kappa Fermi and Bose Distributions}

by Treumann, R. A. and Baumjohann, W. (2021). Front. Phys. 9:672836. doi: 10.3389/fphy.2021. 672836

In the original article, we accidentally missed to include some factorized term in Eqs 19 and 20 when resubmitting the article:

A correction has been made to Section 5: The Kappa Bose Distribution section. The corrected "Equations," completed by the last bracketed factor, read:

Eq. (19):

$$
\left\langle n_{\alpha}\right\rangle_{\mathrm{OB}}=\left\{\left[1-\beta\left(\mu-\epsilon_{\alpha}\right) / \kappa\right]^{(\kappa+s)}-1\right\}^{-1+1 /(\kappa+s)}\left[1-\beta\left(\mu-\epsilon_{\alpha}\right) / \kappa\right]^{-2}
$$

Eq. (20):

$$
Z_{\mathrm{OB}} \equiv \sum_{\alpha}\left\langle n_{\alpha}\right\rangle_{\mathrm{OB}}=\sum_{\alpha}\left\{\left[1-\beta\left(\mu-\epsilon_{\alpha}\right) / \kappa\right]^{(\kappa+s)}-1\right\}^{-1+1 /(\kappa+s)}\left[1-\beta\left(\mu-\epsilon_{\alpha}\right) / \kappa\right]^{-2}
$$

The authors apologize for this error and state that this does not change the scientific conclusions of the article in any way. The original article has been updated.

Copyright () 2021 Treumann and Baumjohann. This is an open-access article distributed under the terms of the Creative Commons Attribution License (CC BY). The use, distribution or reproduction in other forums is permitted, provided the original author(s) and the copyright owner(s) are credited and that the original publication in this journal is cited, in accordance with accepted academic practice. No use, distribution or reproduction is permitted which does not comply with these terms. 